\title{
The Right to be Wrong: Examining the (Im) possibilities of Regulating Fake News while Preserving the Freedom of Expression in Kenya
}

Abdulmalik Sugow*

\section{Abstract}

With the proliferation of peer-to-peer networks as a source of information, concerns on the accuracy of information shared have been raised, necessitating attempts by governments to regulate fake news. Kenya's Computer Misuse and Cybercrimes Act, for instance, criminalises the intentional dissemination of false or misleading data. However, such regulation has resulted in a different set of concerns, particularly its potential to bring about undue limitation on the freedom of expression. In appraising the approach taken in Kenya of imposing liability on perpetrators, and that taken in some jurisdictions of imposing intermediary liability, the article posits that similar difficulties are faced in regulating fake news - the freedom of expression could be curtailed. This is fuelled by ambiguity in the definition of 'fake news'. Consequently, this article seeks to find out if indeed, it is possible to regulate fake news while preserving the freedom of expression in Kenya. Further, the article delves into some of the effects the proliferation of fake news has had on the democratic process in Kenya, thereby requiring regulation. In doing so, it tackles fake news from two general conceptions: fake news as calculated disinformation campaigns by individuals for certain purposes, and fake news as an overarching culture of misinformation that enables the spread of false information. Regarding the former, it finds that legislative measures may prove sufficient. However, the latter requires a combination of non-legislative measures such as collaborative measure, awareness initiatives and fact-checking.

Key words: fake news, freedom of expression, misinformation, democracy

* The author is an LL.B student at the Strathmore University Law School in Nairobi, Kenya. He wishes to acknowledge Mr Cecil Yongo, Mr Arnold Nciko and Ms Sandra Bucha for their constructive feedback throughout the process. 


\section{Introduction}

'In the realm of religious faith, and in that of political belief, sharp differences arise. In both fields, the tenets of one man may seem the rankest error to his neighbour. To persuade others to his own point of view, the pleader, as we know, at times resorts to exaggerations, to vilification of men who have been, or are, prominent in church or state, and even to false statement. But the people of this nation have ordained, in light of the history, that, in spite of the probability of excesses and abuses, these liberties are, in the long view, essential to enlightened opinion and right conduct on the part of the citizens of a democracy? ${ }^{\prime}$

The Supreme Court of the United States aptly set out two important concepts for the discussion contained in this article: the possibility of excesses in differing opinions, and the importance of the right to hold and share those opinions. In Kenya the right to hold and share these opinions has constitutional foundations. ${ }^{2}$ The example of the United States (US) is instructive in the context of this article, as there has been considerable documentation of and discourse on fake news and its effects on the democratic process, especially following the recent 2016 elections.

Fake news has come to be widely regarded as false and misleading content that purports to be true, and is intentionally disseminated on traditional forms of media or on social media. ${ }^{3}$ However, this is simply one of the conceptions that will be dealt with in this article. The other will be the wider culture of fake news, which, this article posits, is the general prevalence of misinformation spread through unintentional means, owing to a lack of fact-checking, and a habit of sharing information that confirms one's biases. ${ }^{4}$ The importance of approaching fake news from these two conceptions is that the latter - which will be termed the cultural conception - often enables the former, which will be referred to as the deliberate conception. Therefore, seeking to define and regulate the direct act of disseminating false information may prove futile if the culture that enables it goes unaddressed. This will be shown further in section II of this article.

At this point, it is crucial to make a distinction between disinformation and misinformation. While both refer to false information, in the context of

Cantwell v Connecticut (1940), The Supreme Court of the United States.

Article 33, Constitution of Kenya (2010).

Allcott H and Gentzkow M, 'Social media and fake news in the 2016 election,' 31(2) Journal of Economic Perspectives, 2017, 213.

4 Tornberg P, 'Echo chambers and viral misinformation: Modelling fake news as complex contagion,' 13(9) PLoS One, 2018, 16. 
this article, disinformation refers to that which is intentionally false, while misinformation is often the result of error. ${ }^{5}$ Therefore the former will be used in reference to the deliberate conception and the latter to the cultural conception.

During the 2016 US general election, there was believed to be an unprecedented amount of false information and propaganda circulating on social media platforms regarding the presidential candidates. ${ }^{6}$ This was to an extent that necessitated an empirical study on the influence that 'fake news' had on the election. ${ }^{7}$ This scenario flows from the belief that established paradigms of electoral campaigns have shifted and social media has been brought to the fore. This shift has brought about concerns regarding the veracity of information shared due to the low barriers to entry, lack of third-party fact-checking or even editorial judgment as noted by Allcott and Gentzkow. ${ }^{8}$

These concerns were exacerbated by the prevalence of fake news on social media platforms such as Twitter in the run-up to the 2016 election in the US. ${ }^{9}$ A large number of people received their news on social media and-as one study has shown $-{ }^{10}$ a significant number of articles containing fake news were circulated online. ${ }^{11}$ Fake news is indisputably dangerous in such a context since it erodes the notion of authoritative and credible sources, and hinders the democratic process. The prevalence of false information influences the decision making of voters, who may be manipulated by calculated disinformation campaigns or outright false claims. ${ }^{12}$ Of course, this argument stems from the belief that democracy is

5 Haldevang M, "Misinformation" is Dictionary.com's word of the year. Don't confuse it with “disinformation”", Quartz Africa, 28 November 2018, -< https:/ /qz.com/1476670/misinformationis-dictionary-coms-word-of-the-year-dont-confuse-it-with-disinformation/ on 9 December 2018.

6 Barthel M, Mitchell M, and Holcomb J, 'Many Americans believe fake news is sowing confusion', Pew Research Centre 15 December 2016.

7 Gunther R, Nisbet E and Beck P, 'Fake news did have a significant impact on the vote in the 2016 election: Original full-length version with methodological appendix' Ohio State University, 2016. See also Gunther R, Nisbet E and Beck P, 'Trump may owe his victory to "fake news," ' study suggests' The Conversation, 15 February 2018.

8 Allcott and Gentzkow, 'Social media and fake news in the 2016 election,' 211-212.

9 Makse H, and Bovet A, 'Influence of fake news in Twitter during the 2016 US Presidential election' Cornell University Library, 22 March, 2018, -< https://arxiv.org/abs/1803.08491 on 8 November 2018.

10 Gottfried J and Shearer E, 'News use across social media platforms 2016', Pew Research Centre, 26 May 2016, -<http://www.journalism.org/2016/05/26/news-use-across-social-mediaplatforms-2016/> on 6 August 2018.

11 Allcott and Gentzkow, 'Social media and fake news in the 2016 election', 227.

12 Persily N, 'The U.S 2016 election: Can democracy survive the internet?' 28(2) Journal of Democracy, 2017, 68 . 
hinged upon people being on the same page with regard to objective facts. ${ }^{13}$ Once this common ground is taken away, decisions that are made may be questioned on the basis that they are not in consonance with the true will of the people. ${ }^{14}$ This concern is especially valid where disinformation and misinformation crop up during electioneering periods, such as in Kenya. ${ }^{15}$ As a result, there has been an effort to minimise the impact that fake news has on people by stakeholders such as Facebook. ${ }^{16}$ A recognition of this in Kenya has also led to a resolve by the US embassy to support the fight against misinformation. ${ }^{17}$ Furthermore, social media websites have run awareness campaigns and attempted to regulate advertisement companies due to the potentially false information they may be spreading. ${ }^{18}$

This push is not exclusive to the US. Persily suggests that the erosion of institutions such as traditional media has led to an internet-driven age of populism where misinformation is rife and heavily influences outcomes. ${ }^{19}$ One such example of a populist movement driven by misinformation is the United Kingdom (UK) referendum to leave the European Union (Brexit vote). ${ }^{20}$ Therefore, following this new age of populism in the media, various countries have attempted to regulate the proliferation of fake news online so as to guarantee their democratic processes. ${ }^{21}$ That is, to ensure that false information and propaganda do not influence voters - which can be surmised from the general politics surrounding the regulations and the period they tend to have been enacted: usually during an election period or following one. For instance, Germany enacted the Network Enforcement Act, ${ }^{22}$ Malaysia, the Anti-Fake News Act, ${ }^{23}$ and both France and

13 Lewandowsky S, Ecker H, Seifert C, Schwarz N and Cook J, 'Misinformation and its correction: Continued influence and successful debiasing' 13(3), Association for Psychological Science, 2012, 107.

14 Lewandowsky, 'Misinformation and its correction, 107.

15 Dahir A, 'Fake news is already disrupting Kenya's high-stakes election campaign' QuartzAfrica, 25 June 2017, -< https://qz.com/africa/1011989/fake-news-and-misinformation-are-upstagingkenyas-upcoming-high-stakes-election/ on 10 December 2018.

16 Isaac M, 'Facebook mounts effort to limit tide of fake news', Nerw York Times, 15 December 2016.

17 Dahir A, 'The US is trying to teach Kenyans how to fight "fake news", QuartzAfrica, 21 April 2018.

18 Hern A, 'New Facebook controls aim to regulate political ads and fight fake news' The Guardian, 6 April 2018 -<https://www.theguardian.com/technology/2018/apr/06/facebook-launchescontrols-regulate-ads-publishers> on 1 June 2018.

19 Persily N, 'The U.S 2016 election: Can democracy survive the internet?', 64.

20 Persily, 'The U.S 2016 election: Can democracy survive the internet?', 64.

21 Postiglione A, 'Countering fake news in the "Emotional Democracy", Centre for Media Pluralism and Freedom, - < http://cmpf.eui.eu/countering-fake-news-in-the-emotional-democracy/ on 31 October 2018.

22 Network Enforcement Act (Germany, 2017).

23 Anti-Fake Neres Act, (Malaysia, 2018). 
Spain are debating Bills as of June 2018. ${ }^{24}$ A partially comprehensive list was compiled in a study conducted by the Nanyang Technological University in January 2018. So far, apart from the countries listed above, Italy, the US, the Philippines, the UK, Australia, Israel, India and Canada have all contemplated or have successfully approved legislation to counter fake news. ${ }^{25}$ From this it becomes clear that a number of countries believe that proliferation of misinformation indeed poses a threat that necessitates the regulation of the flow of information.

Kenya has not been left out of this trend. Fake news is believed to have featured in the country's 2017 general elections. ${ }^{26} \mathrm{~A}$ lot of misleading information on different sides of the political divide was allegedly circulated. ${ }^{27}$ Even more recently, the Cabinet Secretary for Information, Communication and Technology, Joe Mucheru, remarked that there were 70 cases of inaccurate, misleading or sensational news reported to the Media Council of Kenya. ${ }^{28}$ Following that election period, Kenya passed the Computer Misuse and Cybercrimes Act (herein the Cybercrimes Act). ${ }^{29}$ In the Cybercrimes Act, the intentional publication of false, fictitious or misleading information has been criminalised. ${ }^{30}$ This study posits that this provision essentially targets various conceptions of 'fake news', despite there being a lack of a direct mention of the phrase in the Cybercrimes Act.

As stated at the beginning of this article, the problem with the widespread circulation of fake news is that it delegitimises truth and eradicates the idea of 'trusted sources', that is, reliable purveyors of accurate information. When a barrage of seemingly accurate information is overwhelmingly shared on social networks-where dissemination is instantaneous- democracy is at risk because citizens are no longer on the same page about what is true and what is false. ${ }^{31}$

24 Alberola M, 'Spanish Socialists propose measures to curb online fake news' El Pais, 4 April 2018. See also 'The French fight against fake news' Mathias-Avocats, 24 March $2018-<$ https://www.avocatsmathias.com/actualites/fake-news-french-bill> on 1 June 2018.

25 S. Rajaratnam School of International Studies, Nanyang Technological University, Countering fake news: A survey of global initiatives, 2018, 3.

26 Portland Communications, The reality of fake news in Kenya, 2017, 6. See also Bloggers Association of Kenya, State of the internet Kenya 2017, February 2018, 2, 13, 16.

27 Sambuli N, 'How Kenya became the latest victim of fake news' Al Jazeera, 17 August 2017, $-<$ https:/ / www.aljazeera.com/indepth/opinion/2017/08/kenya-latest-victim-fake-news-170816121455181. html on 31 October 2018.

28 Chepkwony M, 'Tackle fake news to win back trust, media challenged' StandardDigital, 8 December 2018.

29 Computer Misuse and Cybercrimes Act, (Act No. 5 of 2018).)

30 Sections 22-23, Computer Misuse and Cybercrimes Act, (Act No. 5 of 2018).

31 The Information Society Project and The Floyd Abrams Institute for Freedom of Expression, Yale Law School, Fighting fake neres: Workshop report, March 2017, 3. 
In the understanding of former US President Barack Obama, having an open debate on the same facts is paramount to a democracy's success; being unable to discern truth from propaganda is a hurdle to any electoral process that aims to be free and fair. ${ }^{32}$

From the foregoing, it appears that Kenya, like other countries, had this in mind when adopting legislation that sought to regulate the proliferation of fake news. ${ }^{33}$ The Majority Leader of the National Assembly intimated the need for regulation on cybercrime and fake news. ${ }^{34}$ However, the outcome of these regulations has not been entirely positive. Civil rights groups and the media have widely criticised the adoption of these regulations in countries such as Germany, Malaysia and Kenya, for limiting the space for freedom of expression. ${ }^{35}$ Further, in Kenya, the High Court suspended the coming into force of the specific sections, pending a hearing of a petition to determine their constitutionality. ${ }^{36}$

While fake news can be said to have negative effects on a democracy, criminalising its publication can be tantamount to violating one's freedom of expression as well as the freedom of the media, especially when fake news is not clearly and objectively defined. There have been concerns that the term 'misleading information', as referred to in the Cybercrimes Act, can be used as an excuse to clamp down on whistle-blowers or activists and impose criminal sanctions on them. ${ }^{37}$ This approach by the Cybercrimes Act will be referred to as authorcentred owing to its imposition of liability on the primary perpetrator. ${ }^{38}$ On the other hand, the other approach - which will be termed 'intermediary centred' taken by some jurisdictions, involves imposing liability on intermediaries such as

32 Fang M, 'Barrack Obama: Fake news on Facebook hurts democracy' Huffington Post, 17 November 2016, -<https://www.huffingtonpost.com/entry/obama-facebook-fake-news_us_582 deba6e4b099512f815e4a> on 1 June 2018.

33 Sections 22-23, Computer Misuse and Cybercrimes Act (Act No.5 of 2018).

34 National Assembly Hansard Report, 21 March 2018, 9.

35 Human Rights Watch, 'Germany: Flawed social media law', 14 February 2018, -<https://www. hrw.org/news/2018/02/14/germany-flawed-social-media-law>on 1 June 2018. See also, Reuters Staff, 'Malaysian news company seeks to have anti-fake news law revoked' Reuters, 27 April 2018 -<https://www.reuters.com/article/us-malaysia-election-fakenews/malaysian-news-companyseeks-to-have-anti-fake-news-law-revoked-idUSKBN1HY0V0> on 1 June 2018. See also, Muendo M, 'New cybercrime law opens the door to privacy violations, censorship' Business Daily, 30 May 2018 -<https://www.businessdailyafrica.com/corporate/tech/new-cybercrime-law-opens-door-toprivacy-violations--censorship/4258474-4587182-vqmc30/index.html> on 1 June 2018. The Bloggers Association of Kenya $v$ The Attorney General and 5 others (2018) eKLR. Article 19, 'Kenya: Computer Misuse and Cybercrimes Bill 2017, Legal Analysis', 2018. Sections 22-23, Computer Misuse and Cybercrimes Act (Act No.5 of 2018). 
social media sites. This could result in private companies censoring their users. ${ }^{39}$ Therefore, this begs the question, is it possible to regulate fake news while preserving the freedom of expression? It is a difficult question to answer as fake news appears to manifest itself both as direct actions of persons creating and sharing misleading content and as an underlying culture that allows the outcome of these actions to proliferate and thrive - this will be explained further on in the article when defining fake news.

Based on the above considerations, this article, in the following sections, seeks to examine whether it is indeed possible to regulate fake news in Kenya while preserving the freedom of expression. The focus in this article is on transmission of false information by individuals via peer-to-peer platforms such as social media. However, the scope is not limited in application and could be extended to general freedom of expression concerns in transmission through various broadcasting platforms.

The methodology adopted is that of appraising the different approaches taken in regulation by different countries and evaluating the effects on the freedom of expression such approaches have. In doing so, the difficulty in ascertaining what counts as fake news is canvassed in section II, investigating the different conceptions of fake news and the impact they have on the mode of regulation. ${ }^{40}$ Following this, in section III, the author considers freedom of expression in the context of false information in a bid to enunciate the precarious position this freedom is put in. In the same section, an examination of two general approaches (author-centred and intermediary-centred) taken in many of these regulations, is conducted and thereafter appraised with a view to finding out whether it is possible to regulate fake news and preserve the freedom of expression in Kenya. To conclude, the penultimate section outlines the possibilities of regulating fake news from both conceptions, while preserving the freedom of expression, before providing a way forward in the final section.

\section{Defining Fake News}

In this section, the author highlights the difficulties that have arisen in defining fake news and shows how they have contributed to problems currently

39 La Rue F, Report of the Special Rapporteur on the promotion and protection of the right to freedom of opinion and expression, A/HRC/23/40, 2013, 14.

40 These conceptions are, fake news as a direct action and as an overarching culture. 
faced in its regulation. In doing so, two general conceptions of fake news are adopted as outlined below: the first is more direct and easier to regulate, than the second. As previously stated, these are referred to as the deliberate conception and the cultural conception, respectively.

\section{i. The Deliberate Conception}

Defining fake news would appear simple at face value; the term is selfexplanatory. Considering the English definitions of both words, and the definition proffered in the introduction of this article, it is easy to conclude that fake news is inaccurate information masked or passed off as authoritative news about the real world. This simplistic understanding of fake news is the first conception adopted in this article. As Allcott and Gentzkow opined, fake news is simply information that is factually inaccurate, but is presented as objective truth. ${ }^{41}$ Gelfert further elaborates and (in the opinion of this article) improves this view, when he argues that the term itself should be reserved for content that is not only factually inaccurate, but also framed as an accurate assertion; the key aspect being the deliberate and calculated misleading nature of the content. ${ }^{42}$ When discussing this specific conception of fake news, various characteristics are salient: the overtly false nature of the imputed deliberateness in circulation and the use of social media to do so in a way that mimics real news. ${ }^{43}$ However, as per Gelfert, the core issues are the deliberateness and the mimicking of actual news to gain credibility. ${ }^{44}$ Therefore, it may very well be that such a definition which provides clear constituent elements is easier to regulate.

Instantaneous communications have been leveraged to launch coordinated disinformation campaigns that compromise democracies. These have been termed as 'distributed denial-of-democracy attacks', the name being indicative of the dangers disinformation poses to democracies around electoral periods. ${ }^{45}$ With definitions such as, 'fake news is the presentation of false claims that purport to be about the world in a format and with a content that resembles the format and content of legitimate media organisations' ${ }^{46}$ much needed clarity is provided,

Allcott H and Gentzkow M, 'Social media and fake news in the 2016 election,' 211-212.

Gelfert A, 'Fake news: A definition', 38(1) Informal Logic, 2018, 84-117, 88.

Gelfert A, 'Fake news: A definition', 96.

Gelfert A, 'Fake news: A definition', 101.

4 Swislow D, 'The distributed denial of democracy’ Medium, 9 November 2016, $-<$ https://medium. com/@dswis/the-distributed-denial-of-democracy-23ce8a3ad3d8> on 20 July 2018.

46 Levy N, 'The bad news about fake news' 6(8) Social Epistemological Review and Reply Collective, 2017, 20-36, 20. 
enabling the possibility of regulation. Such systematic campaigns are easier to identify through the use of this deliberate conception and would generally be easier to regulate, especially since they are often by design. ${ }^{47}$

In making this assertion, Gelfert is careful to differentiate the basic understanding of intentional factual inaccuracy through error and design. This specific difference is what leads to the classification of such false information as fake news, and not just any type of misinformation like biased journalism. It goes to his two core issues: the deliberate nature and the mimicking of real news sources. ${ }^{48}$ Highlighting these constituent elements of fake news provides a measure for enforcement that may allow for a situation where the freedom of expression is preserved. For example, a coordinated campaign such as that of the Macedonian teenagers involved in the US elections is markedly different from a satirical show such as The $X Y Z$ Show in Kenya and this difference is reflected in the 'design' aspect. ${ }^{49}$ According to this article, design is understood to connote calculation in the packaging and dissemination of a message, purposely aimed at deceiving for a specific reason.

An argument may be made that the satire may also be by design in most instances, but such design is often intended to entertain and poke fun at trending or topical news items, whereas in the example of the Macedonian teenagers the objective was to mislead for financial or other gain. Design further implies a significant change in the impact regulation would have on the freedom of expression, and this is discussed in the subsequent section after the cultural conception has been discussed. Therefore, to sum up the deliberate conception, fake news can be understood as 'deliberate presentation of, typically, false or misleading claims as news, where these are misleading by design. ${ }^{50}$

\section{ii. The Cultural Conception}

While the definition above accounts for systematic disinformation campaigns, and at the same time excludes bona fide errors in the sharing of information such as journalistic mistakes, it fails to capture the overall purpose of regulation. Going by the presupposition that governments seek to entrench a

Gelfert A, 'Fake news: A definition', 99-100.

Gelfert A, 'Fake news: A definition', 96.

49 Banic $\mathrm{V}$ and Smith $\mathrm{A}$, 'Fake news: How a partying Macedonian teen earns thousands publishing lies' NBC News, 9 December 2016, -<https://www.nbcnews.com/news/world/fake-news-howpartying-macedonian-teen-earns-thousands-publishing-lies-n692451> on 25 July 2018.

50 Gelfert A, 'Fake news: A definition', 84. 
culture of truth, the failure is manifested in the existence of a general culture of misinformation despite regulation. This presupposition is based on governments combating fake news so as to protect democracies from undue influences such as conflict regarding basic facts and truths. For example, in France, a Bill was brought forward for the purpose of ensuring all citizens are "on the same page" and aren't exposed to misinformation that may compromise their vote. ${ }^{51}$ There are complexities that go beyond the simple understanding of fake news as information that is false, presented as true and, more importantly, as news. The term is connotative of the general trend of proliferating misinformation, from blatantly false information to accidental factual inaccuracies. ${ }^{52}$ This cultural conception depicts fake news as the culture of disseminating misinformation which is indicative of the breakdown of institutions that safeguarded truth and credibility such as traditional media. As mentioned earlier, this is due to the development of social media as a primary source of information..$^{53}$

For example, as Wardle notes, fake news is not just a specific item or set of items that can be said to be fake. Rather, it is an eco-system that contains various forms of mis- and dis-information. ${ }^{54}$ Accordingly, this conception of fake news needs to be unpacked; the type of content, the motivations for the content posted and the method of dissemination all make up this phenomenon. Regarding the type of content, Wardle highlighted seven different types of misand dis-information that are 'problematic'. They range from false connections (which are headlines incongruent to their corresponding articles) to purely fabricated content. ${ }^{55}$

Between these lies a grey area. For example, there is information that is not intended to harm but is false, such as satire or parody which is often used to poke fun as opposed to creating a certain belief in viewers/readers. ${ }^{56}$ Despite the lack of intent to harm or the 'design' aspect discussed in the deliberate conception, these grey areas could cause similar harm, by eroding basic truths necessary for democracies. For example, Boyd suggested that the more dangerous type of misinformation is not blatant but rather insidious content that is often factual

51 - < https://www.gouvernement.fr/en/fake-news-a-bill-to-combat-the-manipulation-of-information on 6 November 2018.

52 Boyd D, 'Google and Facebook can't just make fake news disappear' Wired.

53 The low barriers of entry and lack of third-party fact-checking means that the culture of sharing false information without verification is easily entrenched.

54 Wardle C, 'Fake news. It's complicated' First draft.

55 Wardle C, 'Fake news. It's complicated' First draft. See also London School of Economics Media Policy Project, Media Policy Brief 20, Fake Neres: Public Policy Responses, 2017, 3.

56 See https://uscupstate.libguides.com/c.php?g=617602\&p=4296880 on 6 November 2018. 
but presented in a slanted manner that leads consumers to certain conclusions. ${ }^{57}$ This is dangerous for three reasons: it misleads, it is difficult to identify, and it is harder to regulate without violating one's right to express one's opinion.

Wardle suggests that the entire 'information ecosystem' needs to be approached holistically so as to arrive at an accurate understanding of the proliferation of false information. ${ }^{58}$ That is to say, one must understand the specific type of content at hand, the process of creation, the motivation behind the creation and the means of dissemination. ${ }^{59}$ Misinformation and disinformation are layered, and a lack of clarity as to what they are leads to the generic use of the term 'fake news'. ${ }^{60}$ While fake news can be clearly defined, as in the deliberate conception, the use in society implies an overarching framework of misinformation that fails to meet the parameters set by Gelfert's definition outlined in the previous part of this section. This framework is better understood under the cultural conception and this -the article contends - is what Kenya and other governments have sought to control. In criminalising the publication of false information, it appears to the author that Kenya aims to deter the proliferation of misinformation - the wider culture as opposed to the specific isolated acts. In seeking to control this, human rights concerns arise because of the wide-ranging nature of this conception of fake news.

An example is the provision in Kenya's Cybercrimes Act on false, misleading or fictitious data that is published intentionally. ${ }^{61}$ From the interpretation given in the Act, partisan or biased journalism could be a punishable offence, as the scope of the offence (false publication) ${ }^{62}$ is very vague and leaves room for a majority of these types of mis- and disinformation including satire, partisan journalism, false connections and bona fide errors in journalism to be penalised. This provision fails to account for the motivation behind the content, and this may be due to the lack of a clear objective set out for the provision, the lack of clear interpretation of key terms in the provision such as 'publication' and the lack of appreciation of the layered nature of false information. ${ }^{63}$

\footnotetext{
Boyd D, 'Google and Facebook can't just make fake news disappear', Wired.

Wardle C, 'Fake news. It's complicated' First Draft, 2017.

Wardle C, 'Fake news. It's complicated' First Draft, 2017.

Wardle C, 'Fake news. It's complicated' First Draft, 2017.

Sections 22-23, Computer Misuse and Cybercrimes Act (No. 5 of 2018).

62 Section 22 Computer Misuse and Cybercrimes Act (No. 5 of 2018) states that this includes publication of false, misleading or fictitious data.

63 The provision fails in the sense that the offence requires intent (the mens rea) and the act of publishing, without providing exception for satirical programmes or news pieces, or even bias in journalism. Section 22, Computer Misuse and Cybercrimes Act (Act No.5 of 2018), simply sets
} 
While the qualification of proving intent in publication must be satisfied, this article contends that it does not serve as a viable check. ${ }^{64}$ It fails to account for a situation where a news source is, say, presenting factual information from a 'biased' point of view. ${ }^{65} \mathrm{It}$ is within their mandate to present facts they have analysed to the public, without fear of censorship or control of a prosecutorial authority. They cannot defend themselves therefore as their action was indeed intentional. Aside from that, hundreds, if not thousands of people intentionally share information regularly without certainty as to the veracity, on peer-topeer networks for example, and because of the trust in these networks, the proliferation is achieved easily. ${ }^{66}$ It is apparent that misinformation is rife, but regulation in a broad manner, such as in the Cybercrimes Act which sweepingly lumps misleading, fictitious and false subsets of data together without offering definitions, creates an opportunity for abuse.

This does not mean that false information should be accepted, in fact, systematic disinformation campaigns that leverage modern, instantaneous technologies should be mitigated. The emergence of peer-to-peer communications as a significant source of information has greatly increased the potential for false information to disseminate ${ }^{67}$ However, in order to mitigate this in a manner that will observe what this article has termed 'the right to be wrong' ${ }^{68}$ - that is, the right to exercise one's freedom of expression - a clear definition of fake news must be arrived at. There must be certain measures to identify systematic disinformation campaigns worthy of being regulated. The danger of these systematic campaigns, according to Wardle, is the way in which they lead consumers to believe them. ${ }^{69}$ The consistency and orderliness in messaging relies on heuristics ${ }^{70}$ to ensure

out the blanket offence of false publication without any qualification such as the design nuances discussed in the first part of this chapter.

64 Section 22(1), Computer Misuse and Cybercrimes Act (No.5 of 2018).

65 A biased point of view may be castigated as 'misleading' which has been listed as part of the offence under Section 22.

66 Wardle C, 'Fake news. It's complicated' First Draft, 2017.

67 Wardle C, 'Fake news. It's complicated' First Draft, 2017.

68 This term has been used frequently in literature to mean the right to have contrasting opinions and convictions, and the right to express them. For example, the newspaper The Guardian used the phrase to describe Facebook's policy in The Guardian, 'Zuckerberg defends Facebook users' right to be wrong - even Holocaust deniers' 18 July 2018. Available at https://www.theguardian.com/ technology/2018/jul/18/zuckerberg-facebook-holocaust-deniers-censorship On 24 December 2018. See Machan T, 'Is there a right to be wrong?' The Daily Bell, 16 July 2014. On the right to have contrasting religious convictions see Hasson KS, The Right to Be Wrong: Ending the Culture War Over Religion in America, Paperback, 2012.

69 Wardle C, 'Fake news. It's complicated' First Draft, 2017.

70 These are essentially short cuts formed in the brain when processing information. For example, when confronted with multiple sources confirming the same story, it is easy for one to impute 
that people believe and share information that is false, especially in moments of passion. ${ }^{71}$ The cultural conception, in the opinion of this article, is underpinned by Kahneman's 'cognitive ease' theory. That is, the human mind is naturally susceptible to beliefs which do not require much effort to discern the truth; it is easier to believe what confirms one's pre-existing convictions. ${ }^{72}$ This explains how users can unwittingly share false information on social media, consequently forming part and parcel of this overall culture.

Essentially, the deliberate conception could suffice as a definition tailored to mitigate the harm caused by systematic disinformation campaigns, but a failure to address the cultural conception would mean this mitigation would be an exercise in futility. This is because the former is limited to the more deliberate instances of fake news and does not account for the equally harmful but non-intentional aspects. The less deliberate dissemination points to a culture of misinformation, which is much harder to regulate through law because it may result in a situation where the freedom of expression is grossly curtailed.

\section{Fake News as Exercise of the Freedom of Expression}

Moving from the position that freedom of expression is the right of everyone, this article draws the link between persistent regulation of fake news without an objective definition, and the potential violation of the freedom of expression- an objective definition in this case being a measurable one, such as Gelfert's. ${ }^{73}$ The analysis of the violations is two-fold: firstly, it focuses on the substance of regulation, and secondly the enforcement, which covers the two approaches mentioned in the introduction. It then substantiates that it is indeed possible to regulate fake news as understood under the deliberate conception, without infringing on the freedom of expression. However, it also discusses why it would be pointless to do so without addressing the cultural conception, which poses an equal risk, and is much harder to regulate owing to its broad nature.

credibility.

71 Wardle C, 'Fake news. It's complicated' First Draft, 20107.

72 Kahneman D, Thinking, fast and slow, Farrar, Straus and Giroux, New York, 2011, 55.

73 Gelfert A, 'Fake news: A definition', 84-117, 88. 


\section{i. Regulating Fake News: Substance of the regulation}

All persons have the right to seek, receive and impart ideas of all kinds through all mediums (including social media). ${ }^{74}$ This is the case, even in the African Charter on Human and People's Rights. ${ }^{75}$ Importantly, the freedom of expression is not limited to that which is agreeable to everyone, but may also include ideas that shock, offend or even disturb. ${ }^{76}$ This position is not uncommon in jurisdictions such as the United States, where the freedom of expression is placed on a pedestal. ${ }^{77}$ Therefore, it is not farfetched to assert that some forms of misinformation that would fall under the offence of 'false publication' such as bias in journalism or satire, may be protected under this freedom. This flows from the understanding of the freedom as entailing all ideas, including those that may be false.

In Chavunduka v Minister for Home Affairs, the Supreme Court of Zimbabwe outlawed legislation criminalising false publication on the basis that false information is indeed protected under the freedom of expression. ${ }^{78}$ Additionally, in a joint declaration, the United Nations (UN) Special Rapporteur on Freedom of Opinion and others stressed that the right to impart information was not limited to 'correct statements' ${ }^{79}$ However, it is not an absolute freedom; it can be limited. In Article 24, the Constitution of Kenya, 2010 (CoK) sets out that certain rights may be limited by law, out of necessity and in a manner that preserves other rights. ${ }^{80}$ The government, in seeking to limit this freedom, ought to be guided by a test similar to the three-part test outlined in the Universal Declaration of Human Rights (UDHR). ${ }^{81}$ That is, all limitations must be provided for in law, ${ }^{82}$ must be legitimate in aim, ${ }^{83}$ and necessary in a democracy. ${ }^{84}$ Any

74 Article 33, Constitution of Kenya (2010). See also Article 19, International Covenant on Civil and Political Rights, 1 May 1972, 999 UNTS 171.

75 Article 9, African Charter on Human and People's Rights, June 1981, 1520 UNTS 217.

76 Handyside $v$ The United Kingdom, (1976), European Court of Human Rights, para 49.

77 Reno v ACLU (1997), The Supreme Court of the United States.

78 Chavunduka v Minister for Home Affairs (2000), The Supreme Court of Zimbabwe.

79 Joint Declaration on Freedom of Expression and "Fake News", Disinformation and Propaganda -<Propaganda' Article 19, 3 March 2017 -

$<$ https://www.article19.org/resources/joint-declaration-on-freedom-of-expression-and-fake-newsdisinformation-and-propaganda/ > on $21^{\text {st }}$ July 2018.

80 Article 24(1), Constitution of Kenya (2010).

81 Article 29(2), Universal Declaration of Human Rights, 31 July 1990, 590 UNTS 71.

82 Sunday Times $v$ the United Kingdom, ECtHR Judgment of 26 April 1979, para 47.

83 Clause B.(i), Siracusa Principles on the Limitation and Derogation Provisions in the International Covenant on Civil and Political Rights, 1948 UN Doc E/CN.4/1984/4.

84 Clause B.(ii), Siracusa Principles on the Limitation and Derogation Provisions in the International Covenant on Civil and Political Rights, 1948 UN Doc E/CN.4/1984/4. 
limitation of this right ought to be proportionate to the legitimate aim set out. ${ }^{85}$

Having set out that the freedom of expression entails the right to seek, receive and impart ideas, the regulation of fake news could be construed as a limitation on the freedom of expression in the sense that it controls the flow of ideas. Therefore, any claim to legitimacy must be based on this test. It is important for Kenya's law on fake news to conform to Article 24 as read with Article 33 of the CoK. ${ }^{86}$ Further, the same test for limitation is consistent in the International Covenant on Civil and Political Rights (ICCPR), UDHR, African Charter on Human and People's Rights, and the CoK. ${ }^{87}$

For this test to be met, various aspects of the provision must be vetted. Its necessity in a democratic society having been established vide the arguments made in this article regarding the dangers of fake news, the article focuses on the provision in law and proportionality of the sought limitation. With regard to the provision in law, the primary issue that arises is ambiguity. Provisions seeking to limit rights ought to be sufficiently precise so as to enable subjects to regulate their conduct accordingly. ${ }^{88}$ In Section 22(1), the Cybercrimes Act provides that publication of false, misleading or fictitious data is an offence. ${ }^{89} \mathrm{It}$ does so without providing for any definitions within its interpretation section. In Geoffrey Andare v Attorney General $\mathcal{E} 2$ others, this was sufficient ground for Ngugi J, to declare Section 29 of the Kenya Information and Communication Act unconstitutional..$^{9}$ In paragraph 77 of the judgment, the judge questioned the use of ambiguous terms such as 'grossly offensive'. It was further reasoned that such ambiguity may result in a varied understanding of the legislation, making the judicial officer in question the determiner of what constitutes gross offensiveness. Such a situation creates uncertainty in law. Similarly, this article argues that the use of terms such as 'misleading' in the Cybercrimes Act poses the same problem. Where a definition does not exist, misleading content is left to subjective interpretation.

85 Clause A. 10(d), Siracusa Principles on the Limitation and Derogation Provisions in the International Covenant on Civil and Political Rights, 1948 UN Doc E/CN.4/1984/4.

86 Article 24 and 33, Constitution of Kenya (2010).

87 Article 19, International Covenant on Civil and Political Rights, 1 May 1972, 999 UNTS 171. See also, Article 29(2), Universal Declaration of Human Rights, 31 July 1990, 590 UNTS 71. See also, Article 24, Constitution of Kenya (2010). See also, Article 9, African Charter on Human and People's Rights, June 1981,1520 UNTS 217.

${ }_{88}$ Sunday Times $v$ the United Kingdom, ECtHR Judgment of 26 April 1979, para 49.

89 Sections 22(1), Computer Misuse and Cybercrimes Act (Act No. 5 of 2018).

90 Geoffrey Andare v Attorney General \& 2 others (2016), eKLR. 
If this ambiguity remains unconvincing, the lack of proportionality alone may be sufficient to call into question the validity of the limitation. In Okiya Omtatah Okoiti $v$ Communications Authority of Kenya $\& 8$ others, Mativo $\mathrm{J}$ (as he then was), in discussing valid limitations to constitutional rights under Article 24, set out that limitations ought to be judged on: proper purpose, rational connection between measures implemented and objectives desired, the lack of equally effective but less extreme alternatives, and lastly the importance of the purpose juxtaposed to the preservation of the right. ${ }^{91}$ This was in the context of the right to privacy; however, the principle applies fittingly to the discourse in this article.

While the purpose of provisions on false publications may have been proper in objective, there lacks a balance between the preservation of the proper exercise of the right, and the aim sought in regulation. The ambiguity explained in the previous paragraph, combined with the penal sanctions for the offence put the freedom of expression as a whole at risk. This is especially the case where penalties such as fines may have served the same purpose or where the provisions could have specifically targeted false publication only in the context of Article 33's exceptions to the freedom of expression.

Without a clearly defined subject, regulation is difficult and meeting the three-part test may prove daunting. As shown above, Kenya's provisions may not amount to a valid limitation of this freedom. Specifically, Gelfert criticised straightforward definitions ${ }^{92}$ such as those in the Cybercrimes Act. According to Gelfert, they as fail to appreciate the potential for inaccuracies in the bona fide exercise of simplifying complex information for consumers, for example, using analogies to explain scientific phenomena in a manner that does not directly conform to what is being described. ${ }^{93}$

Nonetheless, Kenya has attempted to provide for the 'design' aspect discussed by Gelfert by imputing intent and/or knowledge as a requirement of the offence. However, the country has failed in this respect. This intent and/ or knowledge qualification fails to be sufficient in the opinion of this study. For instance, intentional reporting of facts in a manner that conforms to the news source's biases and convictions could indeed be characterised as misleading

\footnotetext{
91 Okiya Omtatab Okoiti v Communications Authority of Kenya $\& 8$ others (2018) eKLR.

92 This generally refers to definitions that only entail intent and factual inaccuracies and do not account for the nuanced nature of fake news, as Gelfert comprehended. A clearer differentiation is found in Chapter II.

93 Gelfert A, 'Fake news: A definition,' 99.
} 
data, and therefore fake news, under the Cybercrimes Act, yet it is a valid form of expression that states ought to protect. ${ }^{94}$ In fact, before the passing of the Act, Article 19 (a non-governmental organisation) criticised the sweeping nature of the proposed offence as having the potential to curtail journalism and civic engagement, more so because it frames the government as the arbiter of truth. ${ }^{95}$

This article therefore argues that a failure to objectively define fake news has been a significant cause of difficulties faced in regulation. Particularly, in potential freedom of expression concerns. For example, in an analysis reported by the London School of Economics Media Policy Project, it was noted that Italy's attempt to use the terms 'false, exaggerated or tendentious' was expected to bring up human rights concerns on the ground that it was vague enough to lead to the inclusion of protected forms of expression such as parodies. ${ }^{96}$ This analysis contained in the policy brief further criticised the term 'fictitious data' as rendering satirists as potential criminals. ${ }^{97}$

\section{ii. Regulating fake news: Enforcement of the Regulation}

The potential for infringement of the freedom of expression is not only limited to the substance of the regulation but also the enforcement. Regulations have generally provided for two approaches in enforcement: author-centred ${ }^{98}$ and intermediary centred. ${ }^{99}$ The approaches taken by Kenya and Malaysia are centred on the author or 'publisher' of the infringing content while Germany's approach is centred on the intermediary e.g. social media sites. Both approaches also raise human rights concerns.

\section{a. The Author-Centred Approach as Adopted in Kenya}

The Computer Misuse and Cybercrimes Act of Kenya in criminalising false publication states that the offence shall attract a fine and/or jail-time. ${ }^{100}$ While

\footnotetext{
94 General Comment No. 34, Article 19: Freedoms of opinion and expression, UN doc. CCPR/C/ GC/34 12 September 2011, 6.

95 Article 19, 'Kenya: Computer Misuse and Cybercrimes Bill 2017, Legal Analysis', 2018.

96 Tambini D, 'Fake News: Public Policy Responses,' Media Policy Project, London School of Economics and Political Science, 2017, 3.

97 Tambini D, 'Fake News: Public Policy Responses' 3.

98 Section 22, Computer Misuse and Cybercrimes Act (Act No. 5 of 2018) provides for the offence as being individual-centred, punishing those who author and publish the false information.

99 Sections 2 and 3, Network Enforcement Act (Germany, 2017) provides for fines imposed on intermediaries such as social media sites for failure to take down false information upon notification.

100 Sections 22-23, Computer Misuse and Cybercrimes Act, (Act No. 5 of 2018).
} 
it uses the word 'publish' it fails to define it. ${ }^{101}$ The provision of jail time as a penal sanction, however, suggests that it is targeting an individual who authors or shares such content rather than an intermediary. An intermediary within the context of this article refers to the platform through which an individual authors or shares 'fake news' that is most likely to reach a large number of the population.

Penal sanctions are dangerous, especially when advancing from a point where the definition of the offence is wide and ambiguous. Penal sanctions for expressing oneself lack the proportionality expected of any limitation to the freedom of expression. ${ }^{102}$ Such an approach could result in jeopardising the right. This is because some individuals may censor themselves out of fear of prosecution. The same sentiment was upheld by the High Court of Kenya when it declared the offence of criminal defamation unconstitutional. ${ }^{103}$ In this case, the court, in determining whether it was necessary to resort to criminal sanctions for such an offence, looked at the effects it would have on a wide range of persons, as well as whether other forms of punishment could achieve the stated objective. On the former, the court found that criminalisation of defamation would have a stifling effect on the right to speak and know, and on the latter, the court found that civil remedies would suffice in regulating defamation. It specifically stated that a prison sentence was excessive and disproportionate to the limitation on the freedom of expression. ${ }^{104}$ Therefore, aside from the substance of Kenya's provision on fake news being vague, its approach to enforcement also opens up the opportunity for human rights violations.

\section{b. The Intermediary-Centred Approach}

The other approach, which has been taken by Germany in the Network Enforcement Act, targets intermediaries. ${ }^{105}$ Specifically, it provides for the imposition of fines on social media sites that fail to expeditiously pull down infringing content, that is - in this context - fake news. ${ }^{106}$

101 Section 2, Computer Misuse and Cybercrimes Act, (Act No.5 of 2018).

102 Proportionality in this instance addressed the response to the offence. Requisite effort in reaching the objective set out in the Act is that which leads to the attainment of the said objective without compromising on the overall right that is sought to be limited. Setting out jail time in response to false publication may result in self-censorship. This conception of proportionality is in congruence with the case cited next.

103 Jacqueline Okuta $\mathcal{E}$ another $v$ Attonery General and 2 others (2017) eKLR. See also MISAZimbabwe et al v Minister of Justice et al (2016), High Court of Zimbabwe.

104 Jacqueline Okuta E another v Attonery General and 2 others (2017) eKLR.

105 Network Enforcement Act (Germany, 2017).

106 Sections 2 and 3, Network Enforcement Act (Germany, 2017). 
Intermediaries are entities, such as social media sites, that facilitate the flow of information online; they ought to be distinguished from content creators. ${ }^{107}$ This distinction is particularly important when imposing liabilities because intermediaries typically play a passive role. ${ }^{108}$ This role has been recognised in the US as being important enough to the freedom of expression to necessitate provision of immunity from liability for content shared by users. ${ }^{109}$

Imposing liability on intermediaries could result in a situation where they are forced to become arbiters of what counts as infringing content, effectively placing a judicial function in the hands of a private entity. ${ }^{110}$ This was criticised by La Rue, the Special Rapporteur on the Promotion and Protection of the Freedom of Opinion and Expression. In the report, it was suggested that the only instance intermediaries ought to interfere is after judicial intervention, and in a transparent manner. ${ }^{111}$ Intermediaries are more likely to censor their users when the liability regime is strict; they are, after all, businesses driven by the bottom line and any possibility of huge fines will make them err on the side of caution thereby leading to the censorship of their users. ${ }^{112}$

To conclude this section, the lack of clarity on what amounts to fake news when drafting legislation raises concerns that the freedom of expression could/might be violated. Furthermore, the approaches in enforcing whatever regulations have been drafted also raises similar concerns. Since the provision in the Cybercrimes Act fails to specify who a publisher is, intermediary liability can be contemplated, and the already problems discussed can be addressed. Therefore, the question remains, is it possible for Kenya, to regulate fake news and at the same time preserve the freedom of expression?

107 Article 19, Defending freedom of expression and information, internet intermediaries: Dilemma of liability, 2013.

108 Perset K, 'The economic and social role of internet intermediaries', OECD Publishing, 2010. See also, UNESCO, World Trends in Freedom of Expression E Media Development-Special Digital Focus, 2015, 125.

109 Section 230, Communications Decency Act, 47 USC.

110 When the law sets out limits on the content that can be shared, requiring social media sites to pull down content that infringes these limits, it amounts to expecting them to interpret the law and balance one's freedom of expression with the interests sought in regulation.

111 La Rue F, Report of the Special Rapporteur, 2011, 4. The only instance that intervention without judicial action would be allowed is where content goes directly contrary to the terms and conditions of the intermediary.

112 UNESCO, World Trends in Freedom of Expression E Media Development - Special Digital Focus, 2015, 125. 


\section{Preservation of the Freedom of Expression in Regulation: A Balancing Act}

When examining the deliberate conception of fake news, it is indeed possible to come up with a definition that would ensure the freedom of expression is preserved when regulating the misinformation. The definition adopted as meeting this criterion was espoused by Gelfert. ${ }^{113}$ This conception, as will be explained in part $i$ below, includes an appraisal of various other definitions proffered. This part seeks to elucidate the assertion that this conception of fake news provides an opportunity for countries like Kenya to regulate the phenomenon without infringing on the freedom of expression. In doing so, it begins by highlighting some of the perceived faults in other definitions provided. It then scrutinises this definition through the lens of the freedom of expression, checking to see if misinformation that would be protected as a form of expression, falls under it.

\section{i. Gelfert's definition}

Gelfert criticises definitions that suggest only fabricated content amounts to fake news. ${ }^{114}$ This, he argues, is because for inaccurate information to qualify as fake news, it ought to be designed to mislead. It can only be misleading if it is grounded in reality. Fake news gains credibility from aspiring to fill the roles played by genuine news sources, and; in order to do this, they must be linked to real facts, and not be fabricated. ${ }^{115}$ Additionally, he critiques the simplistic assertion of inaccuracy without the qualification of design; it is erroneous because it includes bona fide errors in an attempt to present the truth. ${ }^{116}$ Gelfert's qualification of 'misleading by design' is the reason this article contends the conception could provide a definition fit to set out a valid limitation on the freedom of expression. As stated earlier, any limitation ought to be prescribed for in law, necessary in a democracy and proportionate to the aim of limitation (that is, it ought not to jeopardise the right).

A significant population of Kenya receives their news through traditional means such as radio, television and newspapers. ${ }^{117}$ However, a large number

Gelfert A, 'Fake news: A definition’, 108.

Gelfert A, 'Fake news: A definition', 99.

Gelfert A, 'Fake news: A definition', 100.

Gelfert A, 'Fake news: A definition', 110

17 See -< http://msra.or.ke/documents/conferences/2017/Media-in-Kenya-Life-in-the-Digital-AgeAkinyi-Njeri.pdf on 8 November 2018. 
of the younger generation use social media as their primary source of news. ${ }^{118}$ Therefore, the negative effects of false information are easily amplified as a result of the wide reach social media has. The necessity in regulating fake news lies in the harm caused by it. Disinformation and propaganda are often designed to mislead people and interfere with the public's right to know. Aside from that, they pose a great risk to people's reputations and privacy. ${ }^{119}$ Sometimes, the harm is physical. ${ }^{120}$ The ease of sharing information online has certainly heightened the harm caused by fake news. ${ }^{121}$ As Wardle notes, consistency and coordination in the dissemination of messages that target cognitive biases leads to consumers believing the information. ${ }^{122}$ Therefore, the necessity of regulation is prevalent. The deliberate conception provides for a set of criteria that adequately delineates what fake news is, namely: inaccuracy, design and the mimicking of genuine news. ${ }^{123}$ By dint of this criterion, a narrower scope of regulation is created. As opposed to using blanket statements such as 'intentional publication of misleading statements', governments can narrow it down to the systematic disinformation campaigns that serve to compromise democracies.

If such a definition were to be included in legislation, along with accurate interpretations of operative terms such as 'publisher' and 'misleading', there would be less concern over curtailment of the space for expression. This is because this conception holds that misleading content must be deliberate in nature. This deliberateness is nuanced in the sense that merely sharing content that is false while aware of the falsity would not count as fake news because the person sharing may merely be a third party who lacks ulterior motives in sharing it. ${ }^{124}$ This conception operates at a much higher level. The motive behind creating misleading content by design need not be linked to the content, nor

118 Wangari N, 'African millennials; mobile usage and media consumption' GeoPoll, 27 February 2017, - < https://www.geopoll.com/blog/african-millennials-mobile-usage-and-media-consumption/ on 8 November 2018.

119 Joint Declaration on Freedom of Expression and "Fake News", Disinformation and Propaganda.

120 Fisher M, Cox J and Hermann P, 'Pizzagate: From rumour, to hashtag, to gunfire in D.C'The Washington Post, 6 December 2016 -<https://www.washingtonpost.com/local/pizzagate-fromrumor-to-hashtag-to-gunfire-in-dc/2016/12/06/4c7def50-bbd4-11e6-94ac-3d324840106c_story. $\mathrm{html}$ ?noredirect=on\&utm_term $=.1 \mathrm{fddaa} / \mathrm{fb} 3 \mathrm{fc}>$ on 21July 2018.

121 Gelfert A, 'Fake news: A definition', 102.

122 Wardle C, 'Fake news. It's complicated' FirstDraft.

123 Gelfert A, 'Fake news: A definition', 108.

124 Behind fake news is human intent. This intent is often driven by a specific objective such as financial gain. Third parties who share the information online despite knowing it is false would not be purveyors of fake news as the design was not theirs: 1) they did not frame the content and 2) they lack the ulterior motives necessary to be deemed a purveyor of fake news. Therefore, liability cannot and should not be imposed on them. 
does it require the purveyors' intent to instill specific beliefs in the consumers. ${ }^{125}$ It is more important that the purveyors are fully aware that they are engaging in behaviour that they can reasonably foresee will result in consumers adopting false beliefs and, more importantly, that they are seeking a secondary purpose in misleading people e.g. financial or political gain. ${ }^{126}$ Gelfert gives the example of the Macedonian teenagers who began a website where fake news would be posted and its proliferation would result in advertisement revenue; their interest was not to influence the election, but to mislead people so they could earn money. ${ }^{127}$ Therefore this conception contends that misleading is the goal of fake news. Design here, denotes both intent when sharing and the systemic manner of proliferation. ${ }^{128}$

Automatically, satire, false connections, spun contexts, parodies, poor journalism and many other types of misinformation are excluded by dint of this specific qualification. Satire, for example, presupposes a certain level of media literacy on the part of consumers and therefore cannot be said to mislead by design. ${ }^{129}$ The same can be said of false connections (where the headline twists the contents of the article to attract readers) and spun contexts. Hence the assertion that it may be possible to regulate fake news under this conception without infringing on the freedom of expression. To begin with, the necessity is clear. The enactment in law is possible, and, most importantly, it limits the scope of those who can be held liable and so it would be proportional. ${ }^{130}$ For example, in Uganda, the Constitutional Court upheld the legitimacy of a provision in the Penal Code Act criminalising false news intended to harm, as a result of its deliberate nature. The judge was of the opinion that such a provision did not take away from the freedom of expression, while at the same time recognising that some lies or falsities have an underlying value necessitating protection under freedom of expression e.g. an environmental activist exaggerating statistics so as to give effect to his or her plea to save the environment. ${ }^{131}$

Therefore, with regard to regulating fake news, as understood through

Gelfert A, 'Fake news: A definition', 107.

Gelfert A, 'Fake news: A definition', 107-108.

Gelfert A, 'Fake news: A definition', 107.

Gelfert A, 'Fake news: A definition', 109.

129 Baym G, 'The Daily Show: Discursive integration and reinvention of political journalism' 22(3) Political Communication, 2005, 259-276, 262.

130 Its proportionality would flow from the wide observance of the freedom of expression vis-à-vis the harm being obviated by mitigating 'distributed denial-of-democracy attacks.' Only specific purveyors will be held liable depending on their action meeting the criteria espoused.

131 Charles Onyango Obbo v Attorney General (2000), The Constitutional Court of Uganda 
Gelfert's definition, it is possible without infringing on the freedom of expression. However, fake news as a culture of misinformation is much harder to regulate and this is discussed in the next part.

\section{ii. Fake news as a culture of misinformation}

As has been highlighted above, fake news can be conceived in two different ways: the first and more direct is provided by Gelfert's definition and the second, slightly more intricate, contains interwoven tropes. It is this article's assertion that when Kenya and other governments enact wide-ranging laws that seek to curtail misinformation, they are not only targeting systematic disinformation campaigns but also the whole culture of sharing misinformation. This brings together elements of both the deliberate and cultural conception. This part discusses the cultural conception and examines the possibilities of regulating what seem to be more of a social issue that has legal implications. ${ }^{132}$ The solutions stemming from this aren't necessarily legal in the strict sense, but rather policy geared at social re-engineering, backed by law.

The assertion above flows from understanding the role of regulation through its telos. Governments that have drafted laws or implemented policies aimed at mitigating fake news can be said to have done so out of the worry that a 'posttruth era' was approaching and this would pose a great risk to their democracies. ${ }^{133}$ This post-truth era ties in all the effects that social media and instantaneous communication has had on media coverage and news consumption. ${ }^{134}$ It refers to the detachment of substance from what it is being discussed, particularly in politics; truth has lost its importance and appeals to emotion have been brought to the fore. ${ }^{135}$ This era is characterised by the spreading of misinformation, effectively unchallenged. The manner in which allegations such as that of the former President Barrack Obama of the US not being born in the US gain traction and spread like wild-fire despite the absurdity of the claims, is typical of

132 It compromises democracy.

133 Biette-Timmons N, 'Bullshit and post-truth politics' London School of Economics Blog, 15 February 2018 - < http://blogs.lse.ac.uk/government/2018/02/15/bullshit-and-post-truth-politics/ on 8 November 2018.

134 Al Sheikh A, 'The media in the post-truth era' Al Jazeera, 11 December 2016, - < https://www. aljazeera.com/indepth/opinion/2016/12/media-post-truth-era-161210125419198.html on 8 November, 2018.

135 Flood A, “Post-truth" named word of the year by Oxford Dictionaries' The Guardian, 15 November 2016, -<https://www.theguardian.com/books/2016/nov/15/post-truth-named-word-of-the-yearby-oxford-dictionaries>- on 22 July 2018. 
a post-truth world. ${ }^{136}$

The will of the people ends up being eroded, effectively delegitimising democracy. ${ }^{137}$ The way in which the will of the people erodes was discussed earlier in this article; the erosion of basic truths means that participation in democracy is skewed at best. Tesich wrote about this era more than two decades ago, and it appears that the concept still holds true. The culture of misinformation indicates a deep entrenchment of a post-truth order that values sensationalism, partisanship and sweeping neologisms at the expense of objectivity. ${ }^{138}$ This 'posttruth era' is not only brought about by misinformation facilitated by lowered barriers of entry in social media, ${ }^{139}$ but generally the culture of spreading misinformation of all kinds and this is what the cultural conception encapsulates. Both Wardle and Boyd have discussed this extensively and suggested that fake news connotes something much greater than a specific definition; it explains the whole framework of false information and how a culture of attaching low value to truth has become entrenched. ${ }^{140}$ What does not count as fake news in the deliberate conception still has the potential to mislead and cause harm, under the cultural conception, for example 'click-bait headlines' or factual errors. ${ }^{141}$ More worrying is that this cultural conception cannot be regulated without infringing on the freedom of expression as it amounts to imposing a burden of truth on people when expressing themselves.

This is exactly the issue that motivated this article: the apparent powerlessness of the law when it comes to imposing a burden of truth on people. ${ }^{142}$ The deliberate conception of fake news may provide a sufficient offence which should be enforced and systematic disinformation campaigns mitigated, but the underlying problem still stands. People will still generate false information, and consumers will still share it. Therefore, one may address the systematic cam-

136 Heuristics "kick in" when information that conforms to one's beliefs is provided, therefore said information is often consumed unchallenged. See also, Levy N, 'Nudges in a post-truth world', 43(8) Journal of Medical Ethics, 2017, 497.

137 Tesich S, 'A government of lies' The Nation, 6 January 1992, 13.

138 The Economist, 'The post-truth world; Yes, I'd lie to you' 9 September 2016, -<https://www. economist.com/briefing/2016/09/10/yes-id-lie-to-you on 8 November 2018.

$139 \mathrm{Al}$ Sheikh A, 'The media in the post-truth era' Al Jazeera.

140 Wardle C, 'Fake news. It's complicated' FirstDraft, 16 February 2017. See also Boyd D, ‘Google and Facebook can't just make fake news disappear' Wired, 27 March 2017.

141 Gelfert A, 'Fake news: A definition', 109.

142 Simply put, there is no legal obligation to tell the truth. The ICCPR, Article 33 of the Kenyan Constitution and even the First Amendment of the United States all provide a wide-ranging freedom of expression that is only limited in specific instances; false information does not form part of these limitations. 
paigns, but without understanding why a person would believe a false allegation to the extent causing them to result to violence, ${ }^{143}$ or why such sensational content gains so much traction, it would be an exercise in futility.

This cultural conception of fake news attempts to understand the culture of a 'post-truth era', and regulating this is much harder because it would require the use of blanket offences that have been castigated in previous sections of this article. How can one justify the imposition of liability on a news network for using a sensational headline, or being partisan in its coverage yet the freedom of expression extends to news making? ${ }^{144}$ Therefore, the problem at hand that needs reconciliation is the harm caused by this cultural conception, with the apparent inability to regulate it without infringing on the freedom of expression. This article contends that it is possible to combat the effects of this conception as well. However, an understanding of the situation must be achieved first.

This is why this article contends that leaving the cultural conception of fake news unresolved, means that any form of regulation of the first conception would be futile. Therefore, the challenge of regulating this conception comes about, seeing as it is inextricably linked to the freedom of expression.

\section{The Way Forward}

The deliberate conception has shown that systematic disinformation campaigns are easier to regulate while preserving the freedom of expression. However, with regard to the cultural conception, it is clear that the problem is more social than legal. While drafting laws to account for the definition provided under the deliberate conception would curtail disinformation campaigns, this would be an exercise in futility if governments were to ignore the culture that enables this overall proliferation of false information.

The fact that it is a social issue poses difficulty in proposing solutions; the law can only do so much. For example, no definition could encompass the wideranging nature of this cultural conception without limiting the right to freedom of expression in some way or another. Indeed, it has been recognised that this is a social problem. ${ }^{145}$ Social media sites - which have lately been the frontier of pro-

\footnotetext{
Fisher M, Cox J and Hermann P, 'Pizzagate: From rumour, to hashtag, to gunfire in D.C' The Washington Post, 6 December 2016.

144 Goodwin v UK (1996) 22 EHRR, 123.

145 Katz M, 'The fake news culprit no one wants to identify: You' Wired, 6 December $2017-<$ https://
} 
liferation of fake news ${ }^{146}$ - have run awareness campaigns and even culled some advertisement companies which utilise false narratives to generate revenue. ${ }^{147} \mathrm{Fa}$ cebook in particular has begun layering fact checking protocols in the publication process, even introducing flags to indicate whether content has been fact checked. ${ }^{148}$ However, Boyd has criticised the act of passing the buck to technology because the problem at hand is one that surpasses technological capabilities. ${ }^{149}$

Based on these considerations, this part shall seek to address possibilities in regulating both conceptions of fake news while preserving the freedom of expression in Kenya. As has been settled earlier on, the deliberate conception can be regulated safely through adoption of the definition provided by Gelfert. When it comes to the cultural conception, various strategies ought to be utilised. To begin with, the fact that it is a social problem necessitates social initiatives to combat it. In general, these initiatives should range from educative initiatives to collaborative engagements. Already, several countries have embarked on initiatives as highlighted below.

To start with, Qatar has launched a website that seeks to clear up false and inaccurate stories. ${ }^{150}$ In Malaysia, a verification website was introduced. ${ }^{151}$ However, some have argued that fact-checking and verification are bound to fail, especially when the media is focused on attracting readers/viewers through false balance ${ }^{152}$ and sensationalism. Readers are already primed to accept whatever confirms their world view because they are stuck in their echo chambers; they

www.wired.com/story/fake-news-social-media-danah-boyd/>- on 22 $2^{\text {nd }}$ July 2018.

48 Bell Journalism Review, 15 December 2016 -<https://www.cjr.org/tow_center/facebook_drains_fake_ news_swamp_new_experimental_partnerships.php> on $22^{\text {nd }}$ July 2018. See also Hern A, New Facebook controls aim to regulate political ads and fight fake news' The Guardian, 6 April 2018 -<https://www.theguardian.com/technology/2018/apr/06/facebook-launches-controls-regulateads-publishers $>$ on $22^{\text {nd }}$ July 2018.

149 Boyd D, 'Google and Facebook can't just make fake news disappear' Wired.

150 Scott V, 'Qatar launches new website to counter "fake news", Doha News, 19 September 2017-<https://dohanews.co/qatar-launches-new-website-to-counter-fake-news/>on $22^{\text {nd }}$ July 2018.

151 Shahar F, 'Communications Ministry launces sebenarnya.my to quash fake news, information', New Straits Times, 14 March 2017 -<https://www.nst.com.my/news/2017/03/220604/communicationsministry-launches-sebenarnyamy-quash-fake-news-information $>$ on $22^{\text {nd }}$ July 2018.

152 This refers to the attempts by the media to appease both sides of the divide despite facts leaning towards one side as a result of pursuing readership so as not to be castigated as 'fake news' in this post-truth era. See, Preston P, 'Broadcast news is losing its balance in the post-truth era' The Guardian, 9 September 2012 -<https://www.theguardian.com/media/2012/sep/09/post-truthpolitics-us-broadcasting $>$ on $22^{\text {nd }}$ July 2018. 
would therefore rubbish any attempts to rectify this. ${ }^{153}$ Resulting from this has been a push for other non-legislative measures to complement fact checking such as increasing media literacy. The inculcation of media literacy is a long-term measure that seeks to ensure current and future consumers of information are well armed to discern real from fake and to ensure they do not contribute to the sharing of false information. The Italian government in conjunction with Facebook has rolled out a program to introduce media literacy as part of the high school curriculum. ${ }^{154}$ Similarly, the Taiwanese government introduced into the curriculum, a program designed to enable students identify and combat fake news. ${ }^{155}$

Aside from that, some countries have attempted to use influencers to encourage social norms consistent with responsible information sharing. For example, Indonesia's President, during an event with social media influencers called upon them to contribute to the fight against fake news. ${ }^{156}$

However, there has been a recognised need to involve various parties in this effort. Being a social issue, it is only natural to enjoin stakeholders in entrenching a culture of truth in this post-truth era. Collaboration between governments, extra-governmental, regional and international bodies is a positive step towards this goal. For example, the Association of Southeast Asian Nations announced their collaboration in the fight against fake news. ${ }^{157}$

Aside from that, Claire Wardle's First Draft has been instrumental in collaborating with governments, social media giants such as Facebook, academic institutions, newsrooms and fact checking bodies to combat the effect of fake news at key periods such as during the French elections, even going ahead to set up a website 'Crosscheck' where the electorate could get access to trending news for verification purposes. ${ }^{158}$

153 Borel B, 'Fact checking won't save us from fake news' FiveThirtyEight, $4^{\text {th }}$ January $2017-<$ https:// fivethirtyeight.com/features/fact-checking-wont-save-us-from-fake-news/>on $22^{\text {nd }}$ July 2018.

154 Serhan Y, 'Italy scrambles to fight misinformation ahead of its elections' The Atlantic, 24 February 2018 -<https://www.theatlantic.com/international/archive/2018/02/europe-fakenews $/ 551972 />$ on $22^{\text {nd }}$ July 2018.

155 Smith N, 'Schoolkids in Taiwan will now be taught how to identify fake news' Time, 7 April 2017 -<http://time.com/4730440/taiwan-fake-news-education/>on 22 nd July 20181.

156 The Jakarta Post News Desk, 'Jokowi tells social media influencers to step up fight against fake news' The Jakarta Post, 24 August 2017 -<http://www.thejakartapost.com/news/2017/08/24/jokowitells-social-media-influencers-to-step-up-fight-against-fake-news.html $>$ on $22^{\text {nd }}$ July 2018.

157 ASEAN Secretariat News, 'ASEAN to cooperate on fighting fake news in the region,'- $<,-<$ http:// asean.org/asean-to-cooperate-on-fighting-fake-news-in-the-region/>on $22^{\text {nd }}$ July 2018.

158 Crosscheck home-page, https://crosscheck.firstdraftnews.org/france-en/. See also S. Rajaratnam School of International Studies, Countering fake neres: A survey of global initiatives, 10. 
Some have suggested that these collaborative engagements could culminate in the creation of a non-governmental institution that is mandated to fight fake news at grassroots level by adopting all these non-legislative measures; fact checking, education of both the citizenry and media as well as collaborating with governments and media bodies. ${ }^{159}$

Therefore, it is indeed possible to regulate fake news and preserve the freedom of expression in Kenya, provided that legislation accounts for the deliberate conception, and non-legislative means are implemented to supplement the legislation in existence. This is the first step in promoting a culture of truth in this post-truth world while protecting the right to be wrong.

159 S. Rajaratnam School of International Studies, Countering fake neres: A survey of global initiatives, 12. 